\title{
El sistema de vivienda en España y el papel de las políticas: ¿qué falta por resolver?
}

\author{
Montserrat Pareja-Eastaway \\ Universidad de Barcelona \\ M. ${ }^{\text {a }}$ Teresa Sánchez-Martínez \\ Universidad de Granada
}

\section{Resumen}

Los desequilibrios ocasionados en un determinado sistema de vivienda son potencialmente corregidos por un diseño adecuado y eficiente de la política de vivienda. El derecho a una vivienda en España viene apoyado por la Constitución y, al igual que en otros campos como la educación o la sanidad, es responsabilidad del Estado garantizar que todo ciudadano tenga acceso a la vivienda.

Durante décadas, la política de vivienda en España no ha servido únicamente a este objetivo sino que ha considerado el sector inmobiliario como un elemento dinámico en el crecimiento del PIB español y ha reforzado la expansión y crecimiento del mismo, en particular en lo que concierne a la vivienda en propiedad. A partir del año 2008, la crisis económica y el colapso financiero han tenido unas consecuencias dramáticas en el sistema de vivienda español: la vulnerabilidad financiera de las familias ante la responsabilidad de asumir sus gastos en vivienda, el riesgo al desahucio, las ejecuciones hipotecarias, el número elevado de viviendas vacías y un sector inmobiliario estancado son, entre otras, las más destacadas.

La política de vivienda, hoy más que nunca, debe dar respuesta a muchos de los problemas que presenta la vivienda en España: a los ya tradicionales de asegurar el acceso a una vivienda digna (no necesariamente de propiedad) se le une la urgencia de solucionar graves problemas sociales generados precisamente en este sector.

Palabras clave: provisión de vivienda, accesibilidad, sobrecarga financiera, política de vivienda en España.

Clasificación JEL: D14, H53, I31, I38.

\begin{abstract}
The imbalances observed in the housing sector of a country are potentially corrected by an appropriate design of its housing policy. The right to housing in Spain is recognised in the national Constitution and, as in the case of education or health, the State is responsible for ensuring that every citizen has access to housing.

For decades, the housing policy in Spain has not only served this purpose but it has also promoted the real estate sector as a dynamic growth factor for the Spanish GDP, specially the building of new flats and houses. However, since 2008 the global economic crisis has had dramatic impacts on the Spanish housing system: financial vulnerability of families facing high mortgage payments, increasing risks of home eviction, foreclosures, a high number of vacant homes, and a stagnant real estate sector, among others.

The housing policy must respond, more than ever, to the problems associated to housing in Spain. There exist now some urgent social issues associated to this sector, which add to the
\end{abstract}


usual difficulties for ensuring that the citizens' right to access to housing is guaranteed (and not necessarily promoting ownership as the main form of home tenure, as in the case of the traditional Spanish housing policy).

Keywords: housing provision, accessibility, financial overburden cost, housing policy in Spain.

JEL classification: D14, H53, I31, I38.

\section{Las claves de la provisión de vivienda en Europa: una mirada desde España}

La provisión de vivienda en Europa ha seguido patrones muy distintos en el pasado: desde una alta implicación pública (Suecia, Reino Unido) a la relevancia del apoyo familiar en la consecución de vivienda (países del sur de Europa), los sistemas de vivienda han utilizado diversos mecanismos para asegurar la función residencial en el entorno. En lo relativo a vivienda, España ha sido considerada tradicionalmente como un ejemplo de los sistemas de bienestar clientelistas o mediterráneos (Allen et al., 2004), conformándose como un pilar débil del estado del bienestar. Han sido las redes familiares y de amigos las que han tenido que asumir un rol activo en la provisión de un estándar de calidad de vida ante la insuficiencia de la protección pública. La poca atención prestada al estado del bienestar durante los años de la dictadura no encuentra suficiente compensación en los años posteriores: el incipiente desarrollo del mismo se conjuga con la necesaria reforma de las instituciones ante el reto de la adecuación a las reglas del juego europeas, resultando en una incómoda incapacidad para agrandar la cobertura y alcance del mismo.

Una de las diferencias más ostensibles entre España y otros países europeos es la conceptualización subyacente de lo que se entiende por vivienda social (Scanlon et al., 2014). Mientras que en algunos países del norte de Europa, como por ejemplo Suecia, la provisión de vivienda adquiere un rasgo universalista (garantizar el derecho a una vivienda digna para todos, sin ningún tipo de sesgo social) y en otros con tinte socialdemócrata como Holanda, apuntan a un cierto criterio social configurando modelos de carácter generalista, en buena parte de los países del sur de Europa pasa por ser un aspecto residual (solo en ciertos casos). En España no existe un parque social propiamente dicho, tal como se entiende en el norte de Europa, un parque de viviendas de alquiler con precios controlados, gestionado por entidades públicas o privadas. Las promociones que podrían ser consideradas como parque social en España son las viviendas protegidas o viviendas concertadas, que salen al mercado directamente para su venta con un precio determinado por el Estado por debajo de los precios del mercado. Sin embargo, durante muchos años estas viviendas dejaban de ser protegidas en el momento en que salían al mercado, debiéndose reinvertir constantemente para la construcción de nuevas viviendas protegidas. No existe un parque permanente, destinado a dar una respuesta rápida a la demanda de vivienda con problemas de acceso.

La política de vivienda en España ha seguido un periplo algo diferente a las grandes tendencias de política de vivienda en Europa. Mientras que nuestros vecinos, después 
de la II Guerra Mundial y ante la escasez de viviendas, abogaban en su mayoría por una dotación amplia de vivienda social, asequible y de alquiler, en España, ante tal insuficiencia, el Estado opta por el fomento de la construcción de viviendas a través de una abundante legislación hasta mediados de los setenta: bajo este paraguas legal los promotores disfrutan de amplias ayudas financieras, préstamos cualificados, facilidades de suministros de materiales de la construcción (la llamada política de ayuda «a la piedra») con el objetivo de hacer accesible la compra de vivienda a las diferentes capas de población durante este periodo (Sánchez-Martínez, 2002). Se refuerza la tenencia en propiedad como mecanismo para garantizar el acceso a la vivienda asegurando, de paso, un sector inmobiliario potente y altamente rentable (Trilla, 2010).

A lo largo de los años, la política de vivienda en España, una vez constatado el absoluto desequilibrio en favor de la propiedad, optaba por mantener el statu quo garantizando la asequibilidad a través de la mejora del acceso a la financiación y de subsidios a la oferta y la demanda para la compra de vivienda. De manera secundaria, las acciones públicas en materia de vivienda diseñaban mecanismos, a menudo insuficientes e ineficientes, que supusieran un paliativo a algunos de los problemas más graves como por ejemplo, el acceso a la vivienda de colectivos vulnerables, entre otros, los hogares monoparentales, los jóvenes y los colectivos en situación extrema de pobreza (Leal, 1992).

El sesgo excesivo de la política de vivienda en España hacia la vivienda en propiedad ha limitado el desarrollo de un sector del alquiler robusto y asequible, situación que en los últimos años se percibe por las autoridades públicas como una situación que inexorablemente se debe corregir. En general y desde un punto de vista teórico, las razones por las que se tiende a potenciar la propiedad son varias: como promoción social y red de seguridad, para minimizar los riesgos de inestabilidad política, por las externalidades positivas de mejor mantenimiento del entorno y por el ahorro indirecto que supone, entre otros. Sin embargo, no hay que olvidar que la existencia de un adecuado parque de alquiler también es deseable por diverso motivos: para dotar de opciones para aquellos que no tienen recursos para comprar (jóvenes y hogares con baja renta), para promover la movilidad geográfica, y para mitigar los riesgos de formación de burbujas en el mercado inmobiliario (Pareja-Eastaway y Sánchez-Martínez, 2014). Dos políticas han sido en gran parte responsables de la disminución del alquiler privado en España: los estímulos públicos a la propiedad y las estrictas regulaciones del sector vigentes hasta 1985 que pretendía congelar los alquileres y arrendamientos a largo plazo (Pareja-Eastaway y Sánchez-Martínez, 2010). Al mismo tiempo, el sector de alquiler social ha permanecido en gran medida inexistente (menos de 2 por 100) durante décadas (desde 1950 hasta 2011). Esta ausencia refuerza el papel del alquiler privado como proveedor de vivienda social para los hogares españoles (Pareja-Eastaway y San Martín, 2002).

En un momento de cambio estructural con respecto a la vivienda en España, este artículo tiene como principal objetivo responder a la pregunta que se recoge en el título, a saber: ¿qué falta por resolver en el sistema de vivienda en España? Para ello, 
en primer lugar, se revisa sucintamente el contexto actual del sistema de vivienda, especialmente a la sombra de la crisis hipotecaria, el colapso del sistema financiero y el desempleo persistente. En particular, se presta especial atención a las familias españolas haciendo hincapié en su salud financiera y en situaciones de emergencia habitacional. A continuación se identifican los cambios producidos en las políticas que atañen a la vivienda después de la crisis. Finalmente, a la luz de lo que han sido los resultados tangibles de las políticas de vivienda hasta ahora, se trazan las directrices de lo que debería constituir la hoja de ruta de la política de vivienda en España de acuerdo a los retos a los que debe dar respuesta.

\section{Abordando el contexto del sistema de vivienda en España después de la crisis}

La crisis económica y financiera desencadenada a partir de 2008 ha cambiado completamente las reglas del juego en toda Europa en lo que se refiere a política y mercado de vivienda. No todos los países se han visto afectados de la misma manera por la crisis. En general, aquellos donde el boom inmobiliario tuvo un mayor auge (España, Irlanda) son los que han tenido que hacer frente a las problemáticas más graves, fundamentalmente ocasionadas por impagos hipotecarios, pérdida de vivienda o aumento de situaciones sin hogar. La capacidad de adaptación de los sistemas residenciales ante una situación dominada por la crisis financiera y económica generalizada no es idéntica: tal y como apunta Priemus (2011), en igualdad de condiciones, los sistemas de vivienda más adaptables suelen ser los que tienen un menor número de viviendas en propiedad: cuando, como consecuencia de la crisis, se produce un desplazamiento de la demanda en propiedad a la demanda de alquiler, es conveniente disponer de un mercado de alquiler de tamaño y calidad óptimos y con capacidad para absorber la creciente demanda. Por tanto, los sistemas de vivienda, tales como los holandeses, suizos o alemanes, reaccionan mucho mejor que el inglés, americano o español.

Muchos países se han visto abocados a la puesta en marcha de medidas tácticas que permitan salir al paso sin el diseño de verdaderas líneas de acción estratégica. Aun así, las tendencias en los mercados después de la crisis han determinado un cambio sustancial en las medidas de política de vivienda en Europa. Sin embargo, las políticas de vivienda están directamente determinadas por la trayectoria (path dependence) de las sucesivas medidas que se han adoptado a lo largo de los años (Bengtsson y Ruonavaara, 2010) representando ciertas rigideces ante la necesaria adecuación por el cambio de contexto. De este modo, cambios drásticos en cuanto a esquemas de provisión o corrección de los fallos de mercado son difíciles de diseñar y aplicar en contextos dominados por ciertos apriorismos en la política de vivienda, con escenarios compuestos por determinados agentes e instituciones que impiden cambios ágiles que permitan adaptarse al contexto cambiante. 
Se podría afirmar que a los problemas históricos de acceso a la vivienda en España, no resueltos completamente por ningún tipo de plan o programa diseñado a escala nacional o autonómica, se le suman las urgencias desencadenadas después de la crisis. La insolvencia de muchas familias con cargas hipotecarias elevadas, la vulnerabilidad financiera a la que siguen sometidos todos aquellos hogares que siguen asumiendo su coste de vivienda a cambio de reducir otros gastos del hogar y la práctica imposibilidad de acceso a una vivienda digna por parte de los hogares con menor nivel de renta son, entre otras, algunas de las cuestiones que la política de vivienda debe abordar de manera inmediata. Ante la gravedad de la crisis en el sistema de vivienda en España y la poca flexibilidad de algunos de sus actores, en particular el sector público y el sistema financiero, la ciudadanía y el activismo han tomado la iniciativa ejerciendo presiones para resolver de forma drástica algunos de los problemas ocasionados por la entrada en la tenencia de propiedad de familias con un alto riesgo para hacer frente a sus compromisos financieros.

El futuro diseño de la política de vivienda en España pasa por descifrar el modo en que las condiciones actuales que dibujan el contexto del sistema de vivienda determinan las principales problemáticas de acceso residencial. A algunas de las dificultades de acceso residencial en España que se constataban antes de la crisis determinada fundamentalmente por los elevados precios de la vivienda y la insuficiente dotación de otras formas de tenencia (García Montalvo, 2007; Naredo, 2004), se le añaden un conjunto de aspectos a tener en cuenta.

\subsection{El sobreendeudamiento de los hogares}

A la gravedad de la crisis económica vivida en España desde el año 2008 se le añade un periodo de inestabilidad bancaria y reestructuración financiera que afecta tanto a los hogares como a las instituciones o a las estructuras productivas. La estabilidad financiera de los hogares está en riesgo cuando toman prestadas cantidades que son desproporcionados a sus ingresos. Esta situación se agrava durante condiciones macroeconómicas desfavorables, cuando el desempleo aumenta, los salarios bajan y los activos inmobiliarios pierden valor; la incapacidad de pago de hipotecas contribuye a aumentar la fragilidad financiera de los hogares y la inestabilidad del sistema bancario.

La vivienda es el activo dominante en las carteras de los hogares, sobre todo en el sur de Europa. Después de la crisis, los hogares endeudados se han visto particularmente afectados por el incumplimiento de las obligaciones hipotecarias. Sin embargo, no todos los países europeos se ven afectados por la crisis del crédito, la insolvencia y morosidad de la misma manera. Las diferencias se pueden encontrar en los hábitos y la cultura de la población con respecto a la dependencia de préstamos, en las estructuras financieras y las variables del contexto general. Además de esto, se argumenta que el efecto de la crisis financiera depende en gran medida de la estructura de sus sistemas de vivienda, en particular, el peso relativo de la vivienda propia y de las alternativas de vivienda social existentes para los hogares. Una fuerte 
dependencia de propiedad de vivienda podría contribuir a agravar el problema financiero de los hogares.

En el caso español, la burbuja inmobiliaria impulsada por las facilidades crediticias a las familias, la ausencia de tasaciones oficiales no bancarias, la presión de demanda, las expectativas de generación de altas plusvalías y una relativamente laxa regulación bancaria han tenido consecuencias graves a largo plazo en cuanto a endeudamiento de las familias y también en relación a la solvencia bancaria.

Un análisis de la deuda bruta de los hogares en relación a la renta (ver Gráfico 1) muestra el elevado grado de endeudamiento de los hogares españoles en comparación a otros tres países, Alemania, Francia e Italia. El año 2007, justo antes del inicio de la crisis, la deuda bruta de los hogares españoles ascendía al 132,77 por 100 , punto álgido de la expansión inmobiliaria que presenta graves dificultades para reducirse (115 por 100 en 2013) dados los compromisos a largo plazo adquiridos. Cabe destacar la relativa estabilidad e incluso decrecimiento del endeudamiento de Alemania, el país que de los cuatro escogidos, presenta un sistema de tenencia más equilibrado, con un peso de la vivienda en alquiler por encima del resto.

Hasta hace poco la investigación sobre los mercados de crédito por lo general se centraba en los préstamos a las empresas, mientras que los hogares eran considerados principalmente como proveedores de fondos, en lugar de deudores. Sin embargo, los acontecimientos recientes muestran que los préstamos a los hogares han tenido un papel central en los balances de los bancos y otros intermediarios financieros, así como en el funcionamiento de los mercados financieros y de la economía real (Marhuenda, 2006; Del Rio, 2002). La estabilidad financiera podría verse afectada por el comportamiento de los hogares bajo condiciones macroeconómicas difíciles, dado que los préstamos hipotecarios a los hogares ha sido un segmento de muy rápido crecimiento dentro del crédito total. De hecho, la morosidad hipotecaria en

\section{GRÁFICO 1}

DEUDA BRUTA DE LOS HOGARES EN RELACIÓN A LA RENTA 2003-2013

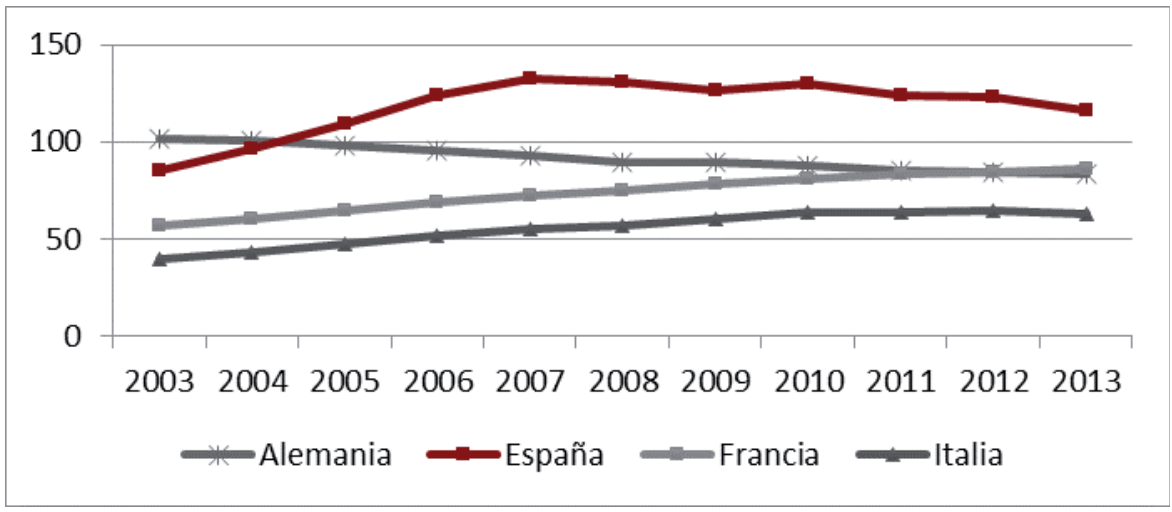

Fuente: Eurostat. 
España ha aumentado sustancialmente ante la crisis: mientras en 2008 se situaba en el 0,5 por 100 , aumenta a 2,4 por 100 hasta el cierre de 2010 y se eleva al 5,9 por 100 en el 2014 (Banco de España, 2014).

\subsection{El mercado de alquiler privado: insuficiente y caro}

Históricamente los hogares españoles se ha visto negativamente afectados por la estrechez del mercado de alquiler (Pareja-Eastaway y San Martín, 2002). En Europa, las familias construyen largas carreras residenciales según sus necesidades y de acuerdo a los sucesivos cambios estructurales en cuanto a composición del hogar, ingresos, estabilidad laboral, etcétera (Mulder, 2001), expandiéndose hacia cada una de las posibles alternativas que ofrezca el mercado de vivienda, bien sea el alquiler privado, el alquiler público ofrecido por una cooperativa, una tenencia compartida o una vivienda de propiedad temporal. Sin embargo, los hogares españoles muestran carreras residenciales muy poco complejas y orientadas en último término a la vivienda en propiedad.

En situaciones extremas como la provocada por la crisis de 2008, la capacidad de resistencia financiera de los hogares que han comprado una vivienda asumiendo elevadas cargas financieras se ve enormemente alterada. En el momento en que se produce un cambio profundo en el contexto y las trayectorias de las familias (desempleo, inestabilidad en la percepción de rentas, etcétera), los hogares que se han convertido en propietarios, ante la imposibilidad de alquilar, son altamente dependientes de sus respectivos lazos de apoyo familiar, del propio sistema financiero y su control sobre el endeudamiento de los hogares y, finalmente, la política de vivienda y los instrumentos que ésta haya definido para hacer frente a perturbaciones negativas como la crisis económica (Cano et al., 2013).

Según los datos del Censo 2011, el mercado de alquiler en España representa el 13,48 por 100 de las viviendas; según las proyecciones de la EU-SILC ${ }^{1}$ a 2012, el mercado de alquiler se sitúa en el 21 por 100 , siendo el alquiler privado un 12 por $100 \mathrm{y}$ el alquiler por debajo del precio de mercado el 8 por 100, incluyendo vivienda cedida o gratis. A todas luces es evidente la baja dotación de parque de alquiler privado en España, insuficiente para hacer frente a una demanda de vivienda a la que únicamente se le ofrece el alquiler privado como alternativa a la propiedad o la vivienda social, por otro lado, casi irrelevante. La falta de vivienda en alquiler en España ha determinado que los hogares que pertenecen al segmento de bajos ingresos se han visto obligados a comprar en lugar de alquilar. Esto se refleja claramente en la EU-SILC (2012): en el colectivo de personas con ingresos inferiores al 60 por 100 de la renta mediana equivalente, un 72,7 por 100 son propietarios de viviendas en España. Dentro de los propietarios de viviendas con ingresos inferiores al 60 por 100, los que tienen una hipoteca pendiente representan un 24,8 por 100 .

\footnotetext{
${ }^{1}$ European Union Survey on Income and Living Conditions
} 
Tal y como se observa en el Gráfico 2, alrededor de un 42 por 100 de las familias españolas que viven en alquiler a precios de mercado soporta unos gastos en vivienda superiores al 40 por 100 de la renta disponible. El porcentaje medio de familias e la UE (15) que se encuentra en esta situación es ostensiblemente inferior alcanzando el punto álgido en 2009 al llegar al 27,9 por 100. Los propietarios sin carga hipotecaria son los que cuentan con un menor número de familias con sobreendeudamiento tanto en España como en la UE (15), siendo de especial interés la situación de los propietarios endeudados: después de la crisis se ha reducido el porcentaje de hogares con sobreendeudamiento, fundamentalmente debido a la caída en el número total de hipotecados, dadas las restricciones al crédito que se han llevado a cabo desde el sistema financiero.

\section{GRÁFICO 2}

\section{SOBRECARGA FINANCIERA POR COSTE DE VIVIENDA SEGÚN TENENCIA}

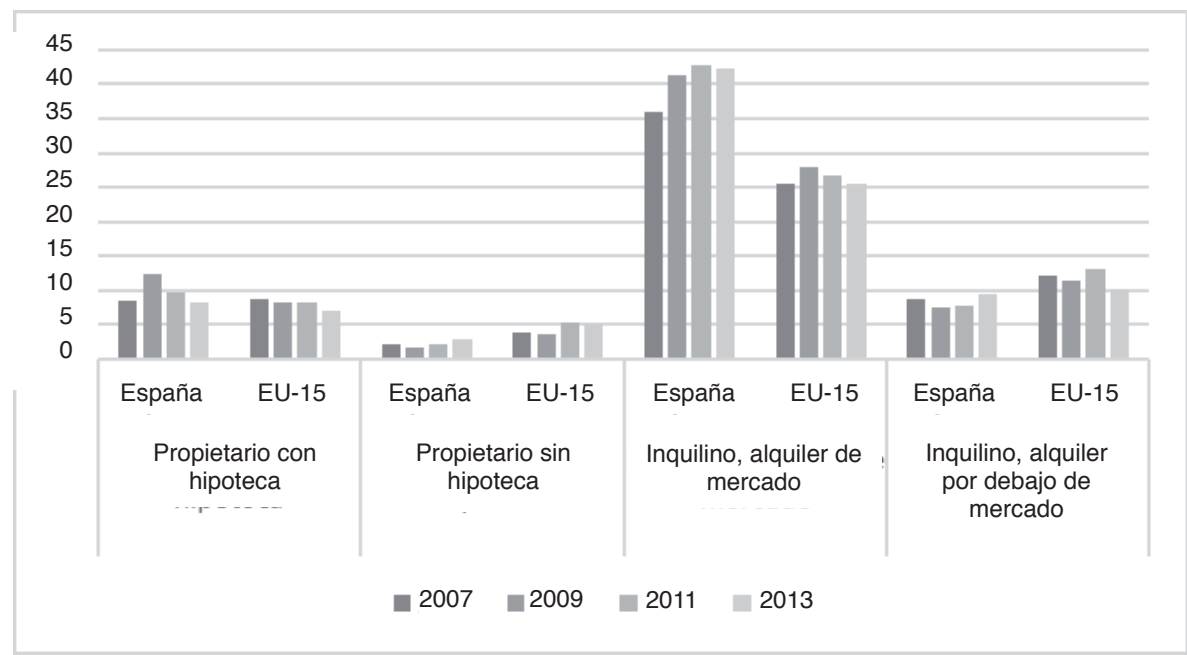

FUENTE: EU-SILC, última actualización 15-9-2015

La existencia de un escaso porcentaje vivienda social, en torno a un 2 por 100 sobre el total de viviendas, lo convierte en insuficiente para atender las necesidades de los grupos vulnerables. Con la llegada de los nuevos hogares maltratados por la crisis junto con los ya de por si numerosos hogares con problemas de accesibilidad a una vivienda digna convierte al alquiler privado en una fórmula alternativa a la vivienda social.

\subsection{Un considerable parque de viviendas vacías}

La burbuja inmobiliaria impulsó la construcción de viviendas en el periodo 2000 al 2007 de forma exponencial: en siete años se ha pasado de terminar casi 
640.000 viviendas anuales a menos de 46.000, según datos de Sociedad de Tasación. La explosión de la burbuja ha conllevado el estancamiento del impulso constructor pero también la aparición de un problema nuevo: las viviendas vacías, acabadas e inacabadas. Buena parte del sector bancario es hoy el propietario de estas viviendas, cedidas o no a la SAREB.

Los resultados del Censo 2011 apuntan a un stock de vivienda vacía de 3.443.365 unidades, un 13,6 por 100 de la totalidad del parque de viviendas. En relación al Censo anterior de 2001, se produjo un aumento de poco más de 300 mil viviendas. Por otro lado, el Ministerio de Fomento (2012) calculaba que en 2012 el stock neto de viviendas no vendidas eran 688.044 unidades y predecía un ajuste progresivo del número de las mismas gracias a la reducción drástica del número de inicios.

Promotores y bancos han optado por diferentes estrategias, entre las que se incluye la creación de la SAREB en 2012, para minimizar el impacto negativo en sus balances no únicamente de la reducción del precio de los activos sino del elevado número de viviendas sin vender. Ante la opción de 'venta al descuento' como la que ha utilizado Bankia recientemente (venta de 4.500 unidades de segunda mano a un precio inferior al anterior en un 40 por 100), se han propuesto otro tipo de alternativas tal y como se verá más adelante, que van en la dirección de usar este parque vacante como instrumento de provisión de vivienda social.

\subsection{Vulnerabilidad financiera de las familias: retrasos, impagos y desahucios}

Los costes de la vivienda se encuentran entre los gastos más significativos de los hogares. En épocas de incertidumbre en cuanto a la percepción de ingresos o de desempleo, los altos costos de vivienda pueden causar a los hogares la reducción de otros gastos no residenciales como la atención sanitaria, la educación o la alimentación. La fragilidad o vulnerabilidad financiera de los hogares viene determinada por el riesgo de incumplir con la obligación del pago de sus deudas. La vulnerabilidad financiera de los hogares depende de su nivel de endeudamiento, de la fragilidad de sus fuentes de ingresos y su capacidad de cumplir sus obligaciones financieras. La principal fuente de incertidumbre proviene de la generación de ingreso laboral, esencialmente determinada por el desempleo (Fuenzalida y Ruiz-Tagle, 2009).

Un análisis en profundidad de la tipología de los hogares en España (véase Cuadro 1) revela el alto porcentaje de familias unipersonales con sobrecarga financiera, en particular, los que tienen menos de 65 años y su creciente evolución a lo largo del periodo 2007-2014. Algo parecido ocurre con los hogares monoparentales con hijos los cuales presentan porcentajes cercanos al 30 por 100 desde 2006 con un valor extremo en 2009 (36 por 100).

Los hogares con dos adultos y tres o más hijos son la tipología de hogar que sigue en cuanto a sobrendeudamiento: aproximadamente, uno de cada cinco hogares está expuesto a un endeudamiento por motivo de vivienda superior al 40 por 100 de su renta disponible. 
CUADRO 1

TIPOLOGÍA DE HOGARES CON SOBRECARGA FINANCIERA

\begin{tabular}{|l|r|r|r|r|r|r|r|r|r|r|}
\hline & $\mathbf{2 0 0 5}$ & $\mathbf{2 0 0 6}$ & $\mathbf{2 0 0 7}$ & $\mathbf{2 0 0 8}$ & $\mathbf{2 0 0 9}$ & $\mathbf{2 0 1 0}$ & $\mathbf{2 0 1 1}$ & $\mathbf{2 0 1 2}$ & $\mathbf{2 0 1 3}$ & $\mathbf{2 0 1 4}$ \\
\hline Unipersonal & 11,2 & 15,1 & 18,7 & 19,3 & 18,3 & 18,3 & 21,2 & 20,3 & 20,3 & 21,5 \\
\hline Unipersonal mujer & 10,2 & 14,9 & 17,9 & 17,1 & 16,4 & 16,9 & 19,0 & 18,2 & 16,5 & 18,5 \\
\hline Unipersonal hombre & 12,6 & 15,3 & 19,8 & 22,0 & 20,5 & 20,0 & 24,0 & 22,9 & 24,5 & 24,8 \\
\hline Unipersonal menor 65 & 16,7 & 20,8 & 26,4 & 28,0 & 26,8 & 24,6 & 29,3 & 29,2 & 29,2 & 32,2 \\
\hline Unipersonal igual o mayor 65 & 5,8 & 8,8 & 10,1 & 8,8 & 7,6 & 9,6 & 9,6 & 8,1 & 8,0 & 6,8 \\
\hline Monoparental con hijos & 16,7 & 28,1 & 29,8 & 29,9 & 36,4 & 32,4 & 30,2 & 28,1 & 28,9 & 31,4 \\
\hline Pareja adultos & 4,6 & 7,1 & 6,9 & 7,4 & 8,1 & 6,4 & 7,8 & 8,1 & 8,6 & 8,3 \\
\hline Pareja adultos menor 65 & 6,6 & 10,5 & 10,5 & 11,1 & 12,2 & 10,1 & 12,3 & 13,2 & 14,0 & 13,6 \\
\hline Pareja adultos uno mayor 65 & 2,3 & 3,0 & 2,5 & 2,5 & 2,6 & 1,9 & 2,6 & 2,3 & 2,7 & 2,8 \\
\hline Pareja adultos con un hijo & 7,4 & 9,2 & 9,9 & 10,8 & 11,1 & 10,7 & 11,4 & 11,6 & 11,8 & 11,7 \\
\hline Pareja adultos con dos hijos & 7,1 & 9,0 & 7,1 & 10,9 & 10,9 & 10,1 & 10,0 & 10,5 & 9,6 & 9,2 \\
\hline $\begin{array}{l}\text { Pareja adultos con tres o más } \\
\text { hijos }\end{array}$ & 10,2 & 8,6 & 11,9 & 21,5 & 21,0 & 19,0 & 17,8 & 20,4 & 18,4 & 19,1 \\
\hline Dos o más adultos sin hijos & 3,2 & 4,8 & 5,5 & 5,3 & 5,8 & 5,5 & 5,7 & 6,1 & 6,2 & 6,8 \\
\hline Dos o más adultos con hijos & 5,9 & 7,7 & 8,2 & 11,7 & 11,9 & 10,6 & 10,5 & 11,7 & 10,8 & 10,8 \\
\hline Tres o más adultos & 1,9 & 2,8 & 4,1 & 3,1 & 3,4 & 4,4 & 3,2 & 3,7 & 3,1 & 4,8 \\
\hline Tres o más adultos con hijos & 2,5 & 5,2 & 6,8 & 10,4 & 10,9 & 8,6 & 7,8 & 10,7 & 8,8 & 8,9 \\
\hline $\begin{array}{l}\text { Hogares sin hijos } \\
\text { dependientes }\end{array}$ & 4,4 & 6,6 & 7,7 & 7,7 & 7,9 & 7,7 & 8,5 & 8,8 & 8,9 & 9,8 \\
\hline $\begin{array}{l}\text { Hogares con hijos } \\
\text { dependientes }\end{array}$ & 6,2 & 8,4 & 8,9 & 12,3 & 12,7 & 11,5 & 11,4 & 12,6 & 11,8 & 12,1 \\
\hline
\end{tabular}

FUENTE: EU-SILC, última actualización 15-9-2015.

El desempleo masivo, el paro de larga duración, el paro juvenil, los hogares con todos sus miembros activos sin empleo, la insuficiencia de las prestaciones y recursos junto la regresión de los instrumentos redistributivos en España, han favorecido el crecimiento y la extensión de la pobreza en España (Trabada, 2012). La tasa de pobreza aumentó en España del 19,7 por 100 en 2007 al 21,8 por 100 en 2011, provocando una de los problemas sociales más graves a los que se ha debido enfrentar la política pública. Con la crisis, se ha agudizado la polarización social en España, concentrándose todavía más en los hogares con ingresos bajos y medios.

Un elemento fundamental para incidir en aquellos altamente perjudicados por la crisis es conocer en qué niveles de renta se está produciendo un mayor sobrecoste de los gastos por vivienda. Una de las clásicas discusiones en el ámbito de la definición de pobreza es la existencia o no de un límite de renta común en Europa para la consideración de pobreza. El criterio del 60 por 100 por debajo de la renta media disponible suele ser el criterio habitual. Sin embargo, ello incluye hogares muy dis- 
pares entre los que se detectan diferentes grados de pobreza extrema o severa (Foessa, 2015). De entre los colectivos que históricamente han presentado un mayor riesgo de pobreza, mientras los hogares con gente mayor han mejorado relativamente su situación, se ha producido una progresiva ‘juvenilización' de la pobreza y un mayor riesgo tanto de los hogares monoparentales como de los titulados universitarios.

Tal y como muestra el Gráfico 3, el primer quintil de renta acumula el mayor porcentaje de familias con sobrecarga financiera por motivo de vivienda; cabe resaltar que mientras en 2007, España presentaba porcentajes menores que la EU, 26,4 por 100 y 30,1 por 100, respectivamente), en 2013 la situación se ha agravado comparativamente mucho más en España en dónde los hogares con sobrecarga financiera por vivienda han pasado a representar un 38,8 por 100 mientras que en la UE (15) supone un 33,5 por 100 .

Los hogares en España presentan históricamente unos ratios muy bajos de morosidad (Valverde y Fernández, 2013). Las distorsiones generadas por la crisis en la economía familiar ha provocado que el sistema financiero español después de la crisis haya tenido que hacer frente a un conjunto de desequilibrios ocasionados tanto por los retrasos/impagos de las hipotecas concedidas en su mayoría durante el boom inmobiliario, como por la acumulación de pasivos no rentables (vivienda inacabada, vacía).

\section{GRÁFICO 3 \\ SOBRECARGA FINANCIERA POR QUINTIL DE RENTA}

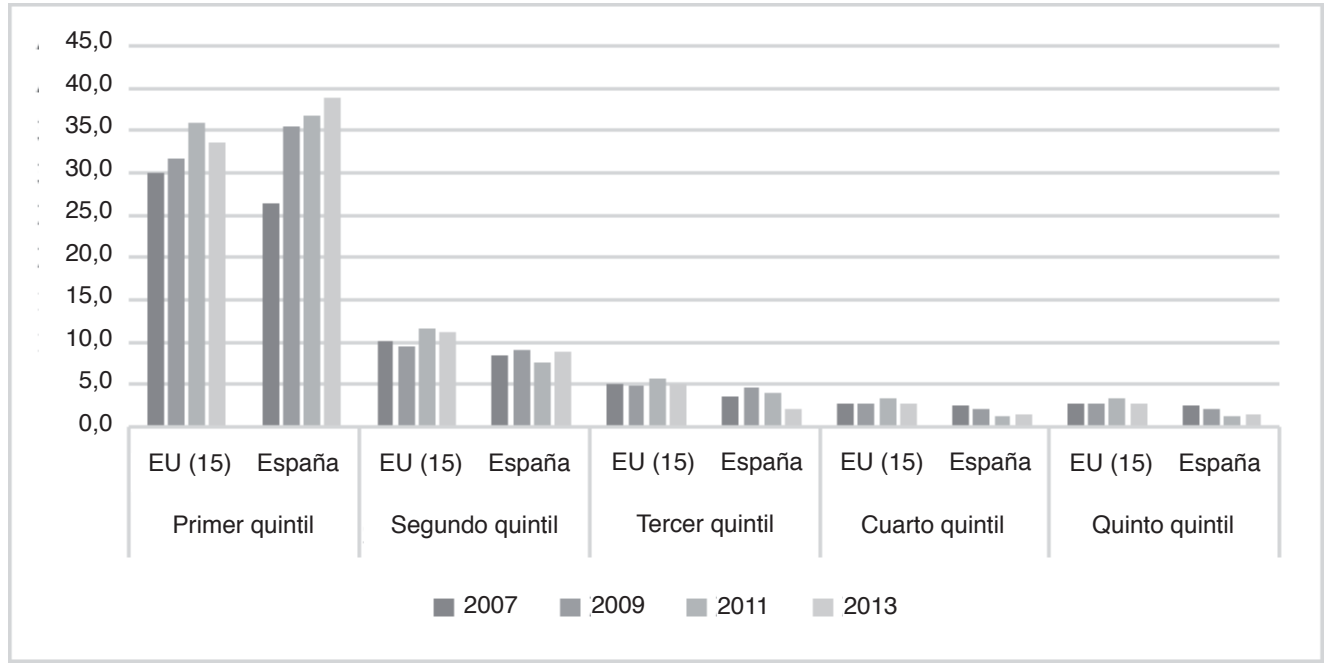

FUENTE: EU-SILC, última actualización 15-9-2015. 
Tal y como muestra el Gráfico 4, los impagos de gastos relacionados con la vivienda han aumentado para todas las familias, en particular para aquellas con un menor nivel de renta (por debajo del 60 por 100 de la mediana de la renta equivalente disponible).

\section{GRÁFICO 4 \\ PORCENTAJE DE FAMILIAS CON IMPAGOS RELACIONADOS CON LA VIVIENDA}

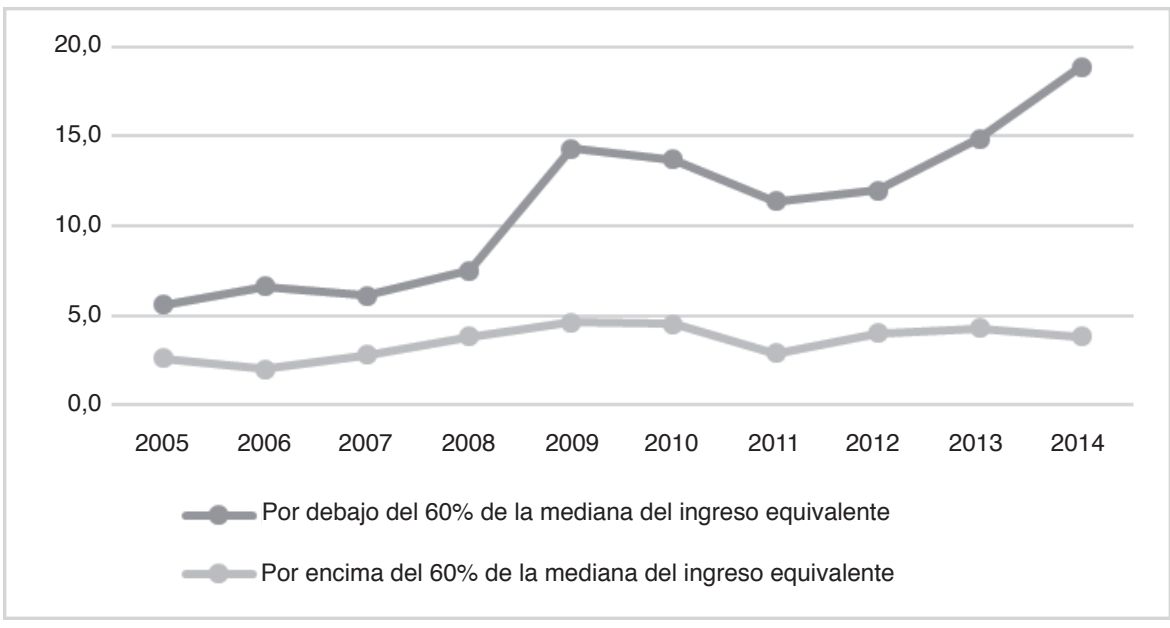

FUENTE: EU-SILC, última actualización 15-9-2015.

En España se han producido 397.954 desahucios en el periodo 2008-2015 (primer trimestre) según datos del Consejo General del Poder Judicial. Esta nueva situación derivada de la crisis implica un nuevo frente para la política de vivienda en España. Hasta ahora dicha política tenía como objetivo básico el de facilitar el acceso a una vivienda digna a los hogares con menos recursos. Después de la crisis, la política de vivienda también debe aportar respuestas a los hogares desahuciados de sus viviendas como consecuencia del impago de sus préstamos hipotecarios o alquileres. Este problema está dando lugar a una nueva tipología de viviendas, las denominadas «viviendas inseguras», según la Tipología Europea de Personas sin Hogar y Exclusión de Vivienda (European Typology of Homelessness and Housing Exclusion) (ETHOS) (Amore et al., 2011). Los desahucios en cadena son una muestra evidente de esta problemática: familias desahuciadas por no poder pagar la hipoteca, y desahuciadas posteriormente por no poder pagar el alquiler privado, y ante la falta de un alquiler social, se ven obligadas a vivir con familiares o amigos, subarrendar habitaciones en pisos o simplemente «ocupar» edificios vacíos. 
GRÁFICO 5

EJECUCIONES HIPOTECARIAS Y LANZAMIENTOS

2008-2014

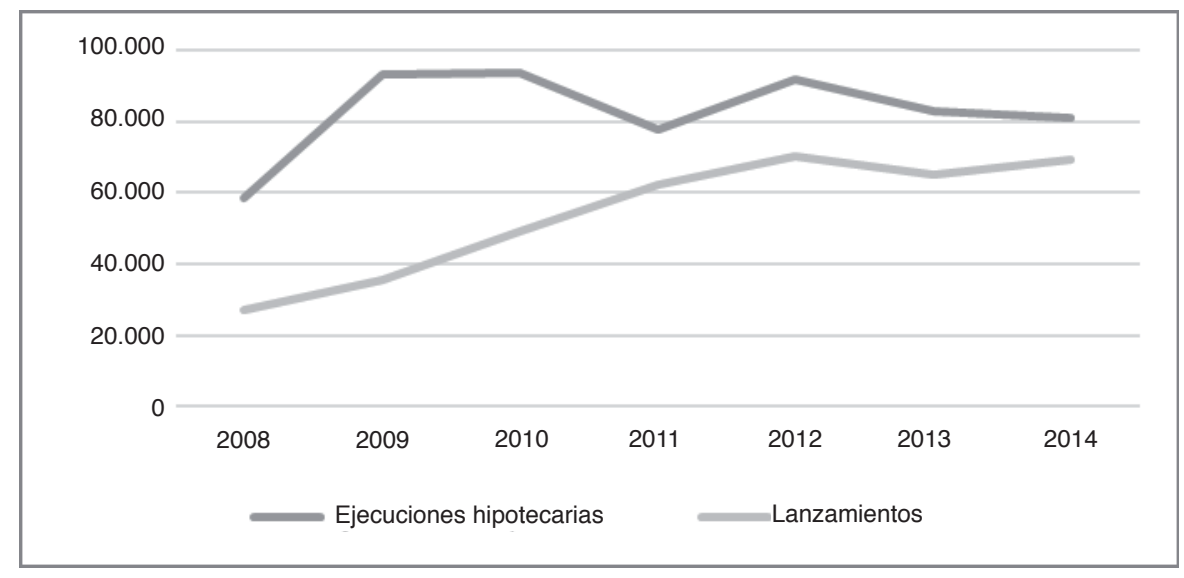

FUENTE: Consejo General del Poder Judicial (CGPJ).

En la última década se han multiplicado por dos el número de españoles que viven en viviendas hipotecadas ya que la mayoría de los nuevos propietarios que accedieron al mercado lo hicieron durante la época de expansión del sector inmobiliario en España. Así, un buen número de hogares españoles acceden a la vivienda en el régimen de propiedad, en primer lugar, por las escasas posibilidades de elegir otra tenencia y, en segundo lugar, empujados por un contexto de euforia crediticia que se lo permitió. En otras palabras, España continúa siendo un país de propietarios (el porcentaje global no ha variado apenas en la última década) pero después de la crisis ha aumentado extraordinariamente el número de hogares hipotecados.

Por consiguiente, los límites de la tenencia en propiedad se han tensionado de manera tan alarmante que amenaza con graves problemas de índole social. Ante la crisis, tal y como se verá posteriormente, la legislación española no dispone de un procedimiento singular para tratar la insolvencia de los ciudadanos. En España no existe lo que comúnmente se conoce como «segundas oportunidades» (Angel y Heitzmann, 2015) para tratar el sobreendeudamiento de los particulares.

\section{Cambios en la política de vivienda en España ante la crisis}

La problemática social de acceso a la vivienda fuertemente acuciada por la crisis plantea un nuevo escenario para la política de vivienda: la aparición de nuevas emergencias habitacionales junto con la necesidad de dar solución a los problemas tradicionales asociados al derecho a una vivienda digna, convierten, al conjunto de mecanismos (públicos pero también privados) para la provisión de vivienda, en un 
elemento clave para dar respuesta al malestar residencial de una parte importante de los hogares españoles.

Para ello, la política de vivienda tiene a su alcance los instrumentos habituales como la provisión de VPO y la orquestación de planes multianuales de vivienda junto con la reformulación de la legislación en el sector del alquiler. Sin embargo, tal y como se verá más adelante, tanto las limitaciones presupuestarias para dotar a las nuevas políticas de recursos para implementar acciones y programas, como el alcance de los replanteamientos de algunas de las medidas propuestas hacen que la gravedad del problema no se vea acompañada por una drástica reorientación de los instrumentos, al menos hasta el momento. Este apartado repasa los cambios reflejados en las principales medidas de política de vivienda ante el escenario residencial después de la crisis.

\subsection{La VPO y los Planes de Vivienda}

La principal forma de vivienda social existente en España ha sido la Vivienda de Protección Oficial en propiedad (VPO). Históricamente se ha caracterizado por su naturaleza contracíclica: en los periodos de expansión en el sector inmobiliario, no existen incentivos a la construcción mientras que en épocas de recesión, la alternativa de la VPO se convierte en más atractiva. No existe, por tanto, una correlación entre el número de inicios y la satisfacción de necesidades de demanda (Pareja-Eastaway y Sánchez-Martínez, 2012). Sin embargo, la actual crisis económica no ha seguido las mismas pautas de recesiones anteriores, por el contrario, al venir acompañada de fuertes restricciones crediticias, no solo ha frenado la construcción de nuevas viviendas protegidas, sino que ha contribuido a resaltar los defectos del sistema (ver Gráfico 6), situándose en 2015 por debajo del 5 por 100 de las ventas totales de viviendas.

\section{GRÁFICO 6}

\section{VIVIENDA PROTECCIÓN OFICIAL. TRANSACCIONES INMOBILIARIAS}

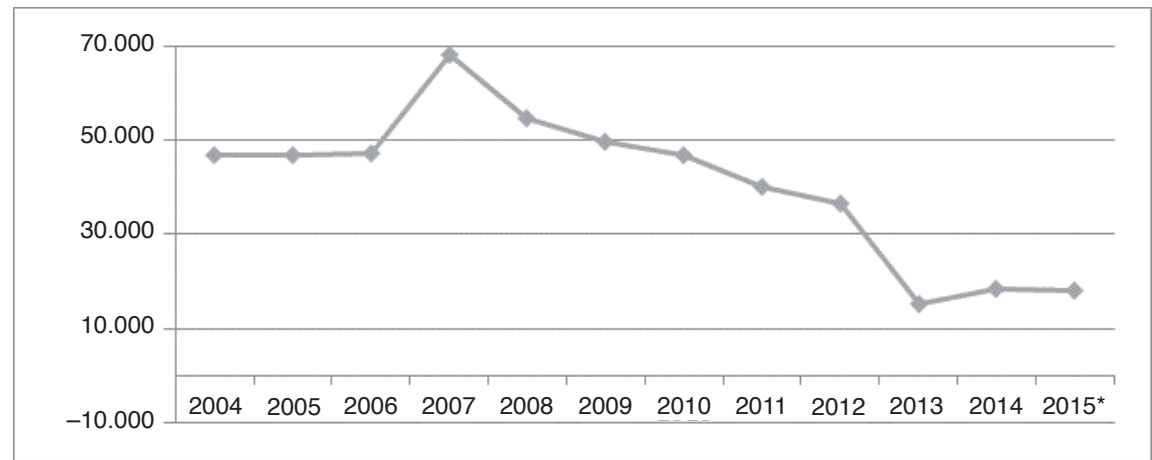

NOTA: * Previsión.

FUENTE: Ministerio de Fomento. 
Durante la crisis el número de transacciones de vivienda protegida ha caído en picado, llegando al suelo mínimo en 2013 con solo 15.264 compra-ventas de vivienda VPO. Esta situación plantea el siguiente interrogante: ¿hasta qué punto puede la VPO en propiedad seguir siendo la figura principal de la política de vivienda en España? Ha sido necesaria una crisis como la actual para empezar a entender por parte de muchos gestores de la política de vivienda que el modelo histórico de derecho a una vivienda, traducido básicamente a la adquisición de la misma carece de sentido. Se trata de un modelo donde todos aquellos beneficiarios que no pudiesen asumir el pago de una hipoteca quedarían fuera del sistema. ¿Qué ocurre entonces con todos aquellos hogares con recursos escasos, con trabajos inestables, población marginal, jóvenes, etc., excluidos a la hora de obtener un préstamo hipotecario?

Este es un modelo que deja la provisión pública de vivienda en manos del mercado, y en última instancia a las decisiones de los intermediarios financieros. A modo de ejemplo, algunos de los demandantes de VPO en propiedad a los que les ha sido asignada una vivienda por sorteo se han visto incapaces de conseguir la hipoteca dadas las condiciones del sistema bancario, dejándoles fuera de una provisión protegida de vivienda al haber optado por la propiedad y no el alquiler. El devenir de los hechos está dando la razón muchos autores que defendían un cambio necesario en el enfoque de las políticas de vivienda hacía el alquiler social (Pareja y Sánchez-Martínez, 2011; Pareja-Eastaway y San Martín, 2002; Leal, 2008; Trilla, 2010; Burón, 2008)

De hecho, los cambios efectuados en el nuevo Plan de Vivienda 2013-2016 reorientan las directrices de la política de vivienda en España hacia mecanismos mayormente orientados a la promoción del alquiler privado y la rehabilitación. La falta de rentabilidad (desde una perspectiva económica que no social) histórica de la promoción de vivienda pública de alquiler requiere en la actualidad de innovaciones en el campo de las fórmulas de provisión así como un replanteamiento del papel asumido por los promotores de vivienda pública.

Por primera vez, el actual Plan Estatal de Viviendas vigente excluye la promoción y la construcción de viviendas con protección pública destinada a la venta. Por el contrario, este programa se centra en el fomento del alquiler y el impulso de la rehabilitación, renovación y regeneración urbanas. Este cambio de orientación es debida, según se explicita en el preámbulo de la Ley, por el ingente stock de viviendas sin vender y la existencia de un gran número de ciudadanos con serías dificultades en el acceso a una vivienda. A ello se une el hecho de la casi equiparación de precios entre los mercados de vivienda libre y protegida, como consecuencia de la explosión de la burbuja inmobiliaria, que deja sin justificación la existencia de estos dos mercados que ahora se solapan (Guillen Navarro, 2014).

De las medidas más novedosas del Plan, y que supone una pieza clave del mismo (ver esquema), está la puesta en marcha de un programa de fomento del parque público de vivienda en alquiler. Se trata de crear un parque público de vivienda protegida de alquiler sobre suelos o edificios de titularidad pública. Los beneficiarios de estas ayudas serán las Administraciones públicas, organismos públicos, ONG, 
fundaciones y asociaciones declaradas de utilidad pública y empresas privadas con derecho de superficie. Este programa cumpliría con la función de aportar una red pública de seguridad en vivienda para todos los colectivos necesitados, la oportunidad de poder acceder a una vivienda pública en alquiler en un momento de emergencia habitacional como el actual. Llegados a este punto, es importante reseñar las dificultades de poner en marcha este proyecto, sobre todo por la falta de experiencia en este tipo de gestión, la escasez de promotores y profesionales, tanto públicos como privados y por los altos costes de gestión de estos parques, así como evitar el estigma que socialmente conllevan muchos de los parques existentes en otros países de nuestro entorno, que han llegado a constituirse como auténticos guetos (Whitehead y Scanlon, 2007; Wassenberg, 2004; Hastings, 2004)

La ejecución del Plan queda en manos de los gobiernos autónomos, los cuales se enfrentan a unos recursos económicos limitados y con pocas posibilidades de desarrollo de las actuaciones previstas. Hasta ahora, prácticamente no se ha avanzado apenas en el desarrollo del plan. Solo se está cumpliendo con el primer programa, la subsidiación de préstamos convenidos, puesto que eran ayudas que ya estaban comprometidas. Los convenios de desarrollo que han de ser firmados con las CCAA se firman muy lentamente y los fondos de financiación no están llegando a su destino (Rodríguez, 2015).

\subsection{La nueva legislación de alquiler}

En general, de manera mayoritaria, los países europeos han utilizado mecanismos alternativos para la provisión de vivienda utilizando conjuntamente algunos de los siguientes sistemas: parques públicos de alquiler, asociaciones de viviendas sin ánimo de lucro que proporcionan alquileres a precios por debajo del mercado a las clases populares, ayudas públicas al pago de alquiler o regulaciones legales de los precios y duración de los alquileres privados. Se evidencia pues que todas estas medidas tienen como común denominador el mercado de alquiler, ya sea público o privado.

Sin embargo, en España el mercado de alquiler ha estado prácticamente relegado a una sola de las anteriores medidas, la de carácter meramente normativo. El estrecho mercado de alquiler existente en España está muy relacionado con su regulación y la incapacidad de la misma para desarrollar una oferta rentable y atractiva. Cubriendo buena parte del espectro, la legislación española sobre vivienda en alquiler oscila desde el control de alquileres y duración de contractos más estricto (Ley de Arrendamientos Urbanos -LAU-, 1964) a la liberalización absoluta (Ley Boyer 1985) a situaciones intermedias en dónde la práctica negociadora entre arrendatario e inquilino tiene la potestad de fijar rentas y duración (LAU, 1994) junto con las últimas variaciones introducidas por la Ley 4/2013, de 4 de junio, de medidas de flexibilización y fomento del mercado del alquiler de viviendas. 
La actual Ley 4/2013, de modificación de la normativa sobre alquileres acorta el periodo mínimo de alquiler de cinco a tres años; disminuye la renovación automática de un contrato de alquiler (en ausencia de estipulaciones específicas en el contrato) de tres años a uno y libera las negociaciones sobre el alquiler mensual (anteriormente vinculadas al índice de los precios al consumo). Los propietarios pueden ahora iniciar un procedimiento civil de desahucio después de un mes del impago del alquiler. La nueva ley de arrendamientos introduce un enfoque más de mercado, que sacrifica en parte los derechos de los inquilinos en aras a liberalizar el mercado del alquiler y hacerlo más atractivo para los oferentes.

En general, la escasa rentabilidad del mercado de alquiler en épocas de expansión ha determinado que los inversores opten por otro tipo de alternativas, sean mobiliarias o inmobiliarias, en detrimento del alquiler. Teniendo en cuenta la elevada atomización de la oferta, ya que la propiedad de vivienda para alquilar se encuentra mayoritariamente en manos de personas físicas (86 por 100), ésta adolece de una necesaria profesionalización en la gestión y se encuentra muy afectada por los vaivenes legislativos que entorpecen la puesta en alquiler por parte de los arrendadores. Todo ello no ha contribuido precisamente a favorecer la expansión del mercado del alquiler.

El Cuadro 2 resume otras medidas e incentivos que, después de la crisis y tanto por el lado de la oferta como por el de la demanda, han buscado potenciar el mercado de alquiler, tanto público como privado, aunque algunas de ellas ya han desaparecido. Entre los incentivos por el lado de la oferta se encuentra la creación de un Fondo de Vivienda Social en el año 2013, acordado entre los Ministerios de Economía y Competitividad y de Servicios Sociales con las principales entidades bancarias de España, mediante el cual se pretende que parte del parque de viviendas vacías que las entidades financieras tienen en cartera fueran habitadas, en régimen de alquiler social, por familias que han perdido su casa y que se encuentran en riesgo de exclusión social. Se constituye inicialmente con algo menos de 6.000 propiedades que aportan las entidades financieras voluntariamente. Aunque los criterios de acceso se han ampliado, sigue siendo una medida de carácter coyuntural, que depende de la «voluntad de las entidades financieras» para adherirse. De cara a fomentar el alquiler privado para los más jóvenes, se implantó una desgravación del 100 por 100 para los propietarios que arrendaban viviendas a inquilinos con edades comprendidas entre 18 y 30 años, sin embargo, esta medida ya no está en vigor desde 2015. También se regula en el actual Plan de Vivienda 2013-2015 la puesta en marcha de un Programa de fomento del parque público de vivienda en alquiler, ya comentado en el epígrafe anterior. 


\section{CUADRO 2}

MEDIDAS DE POLÍTICA PÚBLICA DE INCENTIVO AL ALQUILER

\begin{tabular}{|c|c|c|}
\hline \multicolumn{3}{|c|}{ Incentivos a la oferta } \\
\hline & Programa & Vigencia \\
\hline $\begin{array}{l}\text { Préstamos blandos a arrendado- } \\
\text { res privados para rehabilitar }\end{array}$ & $\begin{array}{l}\text { Plan Estatal de Vivienda 2013- } \\
2016 .\end{array}$ & En vigor \\
\hline $\begin{array}{l}\text { Incentivos fiscales para los pro- } \\
\text { pietarios de alquiler privados } \\
\text { individuales. El arrendador pue- } \\
\text { de aplicarse una reducción del } \\
100 \text { por } 100 \text { de estos rendi- } \\
\text { mientos en el IRPF si los arren- } \\
\text { datarios tienen entre } 18-30 \text { años } \\
\text { y un determinado nivel de ingre- } \\
\text { sos. }\end{array}$ & IRPF & No está en vigor desde 2015 \\
\hline $\begin{array}{l}\text { Creación de un fondo de vi- } \\
\text { vienda social para alquilar }\end{array}$ & $\begin{array}{l}\text { Real Decreto-ley } 27 / 2012 \\
\text { Ley } 1 / 2013 \text {, de } 14 \text { de mayo }\end{array}$ & En vigor \\
\hline $\begin{array}{l}\text { Programa de fomento del parque } \\
\text { público de vivienda en alquiler }\end{array}$ & $\begin{array}{l}\text { Plan Estatal de Vivienda 2013- } \\
2016\end{array}$ & En vigor \\
\hline \multicolumn{3}{|c|}{ Subsidios e incentivos a la demanda } \\
\hline & Programa & Vigencia \\
\hline $\begin{array}{l}\text { Ayudas para facilitar el acceso } \\
\text { y la permanencia en una vi- } \\
\text { vienda en régimen de alquiler } \\
\text { a sectores de población con } \\
\text { escasos medios económicos, de } \\
\text { hasta el } 40 \text { por } 100 \text { del alquiler } \\
\text { anual con ciertos requisitos de } \\
\text { límite renta. }\end{array}$ & $\begin{array}{l}\text { Plan Estatal de Vivienda 2013- } \\
2016\end{array}$ & En vigor \\
\hline Incentivos fiscales & Desgravación fiscal en IRPF & No está en vigor desde 2015 \\
\hline Subsidios para la emancipación & Ministerio de Fomento & No está en vigor \\
\hline
\end{tabular}

FUENTE: Elaboración propia a partir de las distintas normativas.

Por el lado de los incentivos a la demanda de alquiler, se puso en marcha en 2008 la Renta Básica de Emancipación, ya desaparecida. Consistía en una subvención mensual para el pago del alquiler de su vivienda habitual durante un máximo de cuatro años, para facilitar el acceso de los jóvenes con niveles bajos de renta y facilitar así su salida del nido paterno. Algunas Comunidades Autónomas siguen ofreciendo ayudas parecidas. A partir de 2015 desaparece la desgravación fiscal por alquiler de vivienda habitual, que disfrutaban los hogares con rentas inferiores a 24.107 euros anuales. 
La intermediación pública entre la oferta de vivienda vacía y los demandantes de vivienda en alquiler tiene varios ejemplos en las Comunidades Autónomas. Por ejemplo, en el País Vasco está el Programa «Bizigune», que facilita la captación de vivienda vacía de titularidad privada para satisfacer la demanda de arrendamiento a hogares inscritos en Registro de Solicitantes de Vivienda. A través de este programa, los propietarios de viviendas ceden un mínimo de 6 años a la sociedad pública Alokabide sus inmuebles, a cambio de una renta mensual garantizada.

Otro ejemplo es la Xarxa de Mediació para el alquiler social en Cataluña. La Xarxa es un sistema de mediación en el mercado inmobiliario que quiere aumentar la oferta de alquiler a precios moderados y, al mismo tiempo, movilizar el parque de pisos desocupados. Se dirige a hogares de baja renta (ingresos de hasta 4 veces el IRSC (Indicador de renta de suficiencia de Cataluña). Se nutre de viviendas nuevas o de segunda mano, que están vacíos y se ponen en el mercado mediante la gestión de las bolsas de vivienda. Las bolsas gestionan los programas sociales de vivienda en el territorio y dependen de los ayuntamientos, los consejos comarcales y las agrupaciones de municipios.

\subsection{La legislación financiera y los desahucios}

En España, los particulares no pueden proteger su patrimonio frente a una eventual situación de insolvencia, sea cuál sea el origen de sus deudas, y su voluntad de pagar no encuentra una vía para la solución de este problema económico (el Código Civil en España se basa en el principio de «responsabilidad patrimonial universal» de las personas físicas, según el cual el deudor responde incondicionalmente de sus deudas, a través de sus bienes actuales o incluso futuros). La ejecución hipotecaria es la conclusión del problema, lo que agrava la situación, ya que a la deuda inicial hay que añadir el aumento de la misma por los tiempos de tramitación y los gastos e intereses de la ejecución y altos recargos ocasionados por los intereses moratorios que son muy elevados.

El Real Decreto-Ley 1/2015, de 27 de febrero, «de mecanismo de segunda oportunidad, reducción de carga financiera y otras medidas de orden social», propuesto por el gobierno español intenta corregir en parte la carencia antes mencionada que hace referencia a la imposibilidad de renegociar la deuda de los hogares y la ausencia de «segundas oportunidades». Se inspira en el sistema germánico: amplía ligeramente el acceso a la dación en pago, pero sigue sin ofrecer un sistema universal y generalizado para lidiar con la insolvencia particular en España (Gutiérrez y López, 2015).

Desde el año 2012, el Gobierno ha puesto en marcha una serie de medidas destinadas a la protección de los deudores hipotecarios, con singular atención a los que se encuentran en situación de especial vulnerabilidad, que presentan un impacto muy limitado. Son básicamente dos medidas: 
1. Código de Buenas Prácticas que las entidades financieras han de suscribir, el deudor podrá solicitar a la entidad un plan de reestructuración, o una quita o la dación en pago de la vivienda.

2. Suspensión temporal del desahucio. Desde el año 2012, el Gobierno ha puesto en marcha una serie de medidas destinadas a la protección de los deudores hipotecarios, con singular atención a los que se encuentran en situación de especial vulnerabilidad. Su regulación se encuentra en el Real Decretoley 6/2012, de 9 de marzo, de medidas urgentes de protección de deudores hipotecarios sin recursos, en el Real Decreto-ley 27/2012, de 15 de noviembre, de medidas urgentes para reforzar la protección a los deudores hipotecarios y en la Ley 1/2013, de 14 de mayo, de medidas para reforzar la protección a los deudores hipotecarios, reestructuración de deuda y alquiler social, que modifica las dos normas anteriores. Entre otros aspectos, suspende por dos años los desahucios de las familias en especial riesgo de exclusión y modifica la normativa hipotecaria vigente.

3. Por último, para los que han sido ya desahuciados, queda la vía de acudir al Fondo Social de Viviendas para los deudores hipotecarios ya mencionado en apartados anteriores.

A pesar de las medidas expuestas, sigue existiendo en España un vacío legal que incumple la Carta de los Derechos Fundamentales de la UE (como el derecho a la vivienda, la protección al consumidor y el derecho a la dignidad), puesto de manifiesto en un buen número de informes y estudios. Los hogares españoles endeudados necesitan una puerta que permita reestructurar su deuda, desatascar el consumo y prevenir la exclusión social.

\subsection{Otras medidas (movilización la vivienda vacía, tenencias intermedias, innovación social)}

En la actualidad algunas Comunidades Autónomas están tomando medidas fiscales que penalizan el tener la vivienda vacía, con la imposición de impuestos específicos sobre las viviendas vacías o vacantes, recargos en el IBI, o mayores impuestos en el IRPF. Existen además, medidas coercitivas contra los propietarios de las viviendas vacías. En esta línea se sitúa la Ley Catalana 18/2007, de 28 de diciembre, del Derecho a la Vivienda y la Ley 14/2015, de 21 de julio, del impuesto sobre las viviendas vacías, y de modificación de normas tributarias junto con el Decreto Ley 6/2013 de Andalucía de medidas para asegurar la función social de la vivienda. En todos estos casos, a la hora de imponer estas medidas, se produce una complicación importante, que radica en la propia definición legal de una vivienda desocupada y en la imposibilidad en muchos casos de cuantificarlas.

En una línea similar, cuando el problema de los desalojos estaba en su apogeo (marzo de 2013), la Defensora del Pueblo presentó un informe al Parlamento español. 
El objetivo de este informe era llamar la atención sobre la existencia de viviendas de protección oficial vacantes y proporcionar recomendaciones al gobierno para poner fin a la falta de correspondencia entre las necesidades de vivienda y el número de viviendas de protección oficial vacías (Informe Defensor del Pueblo, 2013).

En una operación innovadora, la SAREB firma en un acuerdo para la transferencia de la vivienda en alquiler social con el Gobierno catalán. Se forma al modelo para acuerdos similares con otras regiones para poner fin a dedicar a este fin alrededor de 2.000 edificios. Este primer acuerdo implica la transferencia de 600 viviendas al Departamento de Territorio y Sostenibilidad de Cataluña que gestionará esta población durante un periodo de cuatro años, renovables si así se acuerda por ambas partes. Estas propiedades se utilizarán para proporcionar «viviendas asequibles de alquiler», por montos que oscilan entre los 150 y 400 euros al mes.

Las tenencias intermedias aparecen en España como alternativa a la tradicional dicotomía entre la tenencia en alquiler o en propiedad. Desde hace años que este tema genera un considerable interés en el Reino Unido ya que, entre otros, podría ofrecer una válvula de escape para los propietarios con problemas financieros o para los bancos con acumulación de activos tóxicos además de posibles beneficios para una demanda con un cierto poder adquisitivo (TENLAW, 2013). La propiedad compartida o temporal comportan cambios en la legislación, en particular requieren de una redefinición del concepto de propiedad. Esto ha sucedido ya en Cataluña con la Ley 19/2015, del 29 de julio de incorporación de la propiedad temporal y de la propiedad compartida.

Otro tipo de medidas adoptadas desde la innovación social son las cooperativas de vivienda en régimen de cesión de uso: la cooperativa posee la propiedad o el derecho de construir un bloque y asigna a sus socios el derecho a utilizar una vivienda a cambio del pago de una cantidad inicial y recuperable, así como el pago de una renta periódica asequible. Este modelo es frecuente en Suecia y ha comenzado a explorarse en España (Etxezarreta y Merino, 2013).

\section{Retos de futuro de la política de vivienda en España}

En la política de vivienda en España después de la crisis recaen diversas responsabilidades: por un lado, hacer frente a la emergencia habitacional en la que se encuentra el país, abordando desde los diferentes niveles de gobierno las posibles soluciones, al menos de corto plazo, para ofrecer un hábitat y, por otro, el diseño de un proyecto estratégico de largo o medio plazo de política de vivienda independientemente del ciclo económico.

La reflexión al hilo del artículo sugiere los siguientes elementos a tener en cuenta como puntos de partida para el diseño de una futura política de vivienda en España: en primer lugar, se debe decidir qué modelo de provisión de vivienda parece el más adecuado dadas las circunstancias. La caracterización de la política de vivienda como «residual»o, en otras palabras, dirigida solo a aquellas personas que se encuentran en determinadas condiciones y que cumplen determinados requerimientos sobre todo 
a nivel de renta, deja en manos del mercado la provisión de vivienda para muchos hogares. Una decisión fundamental en materia de política de vivienda responde a la necesidad de determinar a priori qué derechos quieren garantizarse al conjunto de la ciudadanía. Así, la redefinición de un modelo de vivienda social debe responder no únicamente a criterios de justicia social sino también a sus posibilidades de supervivencia en un contexto marcado por la austeridad económica y la disminución progresiva del peso del sector público.

La historia de la política de vivienda convierte a la Vivienda de Protección Oficial (VPO) en la figura más popular y particular del sistema de vivienda en España. Una vivienda social orientada a la propiedad difícilmente tiene cabida en el contexto actual marcado por la grave problemática habitacional y la urgencia de soluciones a corto plazo. Ello no menoscaba la necesidad de replanteamiento de esta figura: ¿hasta qué punto sigue teniendo vigencia el uso de la propiedad como principal mecanismo de provisión de vivienda? El nuevo Plan de vivienda 2013-2016 prescinde por primera vez de la tenencia en propiedad para profundizar en la ayuda a la vivienda de alquiler y la rehabilitación. Sin embargo, ¿qué papel debe asumir la Vivienda de Protección Oficial en alquiler? ¿Hasta qué punto tiene sentido mantener un parque de vivienda pública de baja rentabilidad económica? Los promotores de vivienda pública, ¿podrían ejercer como gestores del patrimonio construido que no puede pasar por el mercado? ¿Podrían dibujarse medidas que favorecieran la compra de vivienda por parte del sector público para que, de acuerdo a las prioridades y emergencias del momento, pudiera responder con un parque de vivienda de propiedad municipal? En España no hay tradición de subsidios directos a las familias (housing allowances) para que ellas decidan cómo y dónde lo quieren gastar para cubrir sus necesidades de vivienda. Resulta difícil imaginar un sistema nuevo de garantía de acceso a la vivienda fundamentado en este tipo de instrumento en un contexto definido por la contención presupuestaria. Ello no significa que, de entrada, no deba contemplarse esta posibilidad y contrastarla con los pros y contras de un sistema, altamente deficitario, basado en un parque de vivienda social.

Un apunte aparte merece el sector del alquiler privado al que a menudo se le exigen demasiadas funciones ante la casi inexistencia de vivienda social pública. En el alquiler compiten hoy demasiadas demandas: los hogares expulsados de la propiedad, los que no pueden acceder a una vivienda en propiedad a precios de mercado, los jóvenes, los que presentan una alta movilidad laboral, los que rechazan la propiedad después del estigma negativo adquirido después de la crisis, etc. Parece imprescindible asegurar una mayor y diversa oferta de alquiler junto con una regulación que responda al aumento de la complejidad de la sociedad española actual. Poner las bases para una profesionalización en la gestión del sector, sin lugar a dudas difícil pero no por ello menos necesaria, supondría un paso adelante en la garantía de funcionamiento del sector que tanto propietarios como inquilinos demandan de la vivienda en alquiler.

Sin lugar a dudas, el contexto propicia el replanteamiento de las directrices de largo plazo de la política de vivienda en España. Ciertamente, la trayectoria o 
path dependency de la política de vivienda dificulta la innovación y la introducción de nuevas formas de tenencia o de provisión residencial. Sin embargo, esto no debe impedir poner en valor las iniciativas que, aún sin contar con masa crítica, proporcionan alternativas a las figuras tradicionales de uso y disfrute de la vivienda. Modelos como las tenencias intermedias o las cooperativas de uso de vivienda representan soluciones que, si bien no necesariamente atractivos para el conjunto de la población, abren nuevas puertas a la dicotomía alquiler y propiedad. Es necesario provocar complementariedades y complicidades entre la innovación social en vivienda y la propia política de vivienda.

\section{Conclusiones}

La política de vivienda en España ha sido habitualmente confundida como uno de los tentáculos de la política económica. Ello ha tenido graves consecuencias para los hogares españoles ya que de manera progresiva se han visto inmersos en un sistema de vivienda en donde la tenencia en propiedad aparece no únicamente como la predominante sino como la mejor posible.

Este desequilibrio en cuanto a tenencia ha representado un agravio comparativo para ciertos propietarios e inquilinos ante la perturbación causada por la crisis económica a partir del año 2008; la inestabilidad laboral y la reducción de los ingresos de las familias caracterizan el peor de los escenarios en los que un porcentaje elevado de los hogares ha tenido que seguir haciendo frente a elevados costes por motivo residencial. Las consecuencias son bien conocidas: impagos, desahucios, retorno a la vivienda parental, sobreocupación de las viviendas por dos o más familias, personas y hogares sin techo, etcétera.

Tal y como se ha visto a lo largo de este artículo, el contexto después de la crisis económica pone de manifiesto las principales consecuencias de las debilidades del sistema de vivienda en España: familias sobreendeudadas, sobrecarga financiera por motivo residencial, viviendas vacías, un mercado del alquiler demasiado estrecho, impagos, desahucios, etcétera. La política de vivienda a escala nacional, muy determinada por un contexto de austeridad y restricción presupuestaria, a duras penas puede hacer frente a los compromisos adquiridos en el pasado. El nuevo Plan de Vivienda emerge limitado por la dotación presupuestaria del mismo y los compromisos adquiridos en el pasado, la legislación del alquiler sigue siendo generalista y excesivamente arbitraria sin abordar las particularidades de las diferentes tipologías de hogares que pueden acceder a esta tenencia, no necesariamente clasificados en el segmento de demanda de mayor vulnerabilidad. La inexistencia de vivienda social en España imposibilita su uso para resolver las emergencias residenciales después de la crisis; su baja rentabilidad económica a pesar de su elevado beneficio social la cuestiona como capaz de garantizar una provisión de vivienda digna para los más vulnerables. 
El sector público debe garantizar, a través de múltiples instrumentos, que las familias tengan acceso a una vivienda adecuada y digna, no necesariamente en propiedad. Durante décadas, la política de vivienda en España ha conllevado la propagación de una «cultura de la propiedad» que ha llevado a muchos hogares a un endeudamiento excesivo con tal de acceder a este régimen de tenencia. Después del impacto de la crisis, el sistema no ha permitido la flexibilidad necesaria para que estas familias siguieran en sus viviendas creando verdaderos casos de emergencia social. La política de vivienda y sus responsables deberían garantizar que esto no suceda nunca más.

\section{Referencias bibliográficas}

[1] ALLEN, A.; BARLOW, J.; LEAL, J.; MALOUTAS, T. y PADOVANI, L. (2004). Housing \& Welfare in Southern Europe. Blackwell Publising.

[2] AMORE, K.; BAKER M. y HOWDEN-CHAPMAN, P. (2011). «The ETHOS definition and classification of homelessness: An analysis». European Journal of Homelessness, 5(2).

[3] ANGEL, S. y HEITZMANN, K. (2015). «Over-indebtedness in Europe: The relevance of country-level variables for the over-indebtedness of private households». Journal of European Social Policy, 25(2), 331-351.

[4] BANCO DE ESPAÑA (2014). Informe de Estabilidad Financiera, noviembre.

[5] BENGTSSON, B. y RUONAVAARA, H. (2010). «Introduction to the special issue: Path dependence in housing». Housing, Theory and Society, 27(3), 193-203.

[6] BURÓN, J. (2008). «Una política de vivienda alternativa».Ciudad y Territorio Estudios Territoriales, XL(155), 9-40.

[7] CANO FUENTES, G.; ETXEZARRETA ETXARRI, A.; DOL, C. P. y HOEKSTRA, J. (2013): «From housing bubble to repossessions: Spain compared to other West European countries». Housing Studies, 28(8), 1197-1217.

[8] DEL RÍO, A. (2002). El endeudamiento de los hogares españoles (228). Banco de España.

[9] ETXEZARRETA, A. y MERINO (2013). «Las cooperativas de vivienda como alternativa al problema de la vivienda en la actual crisis económica». Revesco, núm. 113. Monográfico: «Crisis económica actual y sus posibles repercusiones en la economía social».

[10] FUENZALIDA, M. y RUIZ-TAGLE, J. (2009). «Households' Financial Vulnerability», Central Bank of Chile. Working Papers, núm. 540, diciembre.

[11] GARCÍA-MONTALVO, J. (2007). «Algunas consideraciones sobre el problema de la vivienda en España». Papeles de Economía Española, 113, 138-153.

[12] GUILLÉN NAVARRO, N. A. (2014). «El plan de vivienda 2013-2016: el renacer de la vivienda de alquiler en España». Ciudad y Territorio. Estudios Territoriales, XLVI(182), 591-606.

[13] GUTIÉRREZ, D. y LÓPEZ, J. (2015). «Segundas oportunidades en Europa: tres modelos para un mismo problema». Agenda Pública, 5 de marzo.

[14] HASTINGS, A. (2004). «Stigma and social housing estates: Beyond pathological explanations». Journal of Housing and the Built Environment, 19(3), 233-254.

[15] INFORME DEL DEFENSOR DEL PUEBLO (2013). «Informe sobre viviendas prote- 
gidas vacías». http://www.defensordelpueblo.es/es/Documentacion/Publicaciones/mono grafico/contenido_1363855813805.html.

[16] LEAL, J. (2008). «El cambio de modelo y convergencia con Europa en la política de vivienda social española». Ciudad y Territorio, Estudios Territoriales, XLI(161-162), 489-504.

[17] LEAL, J. (coord.) (1992). Informe para una nueva política de vivienda. Ministerio de Obras Públicas y Transportes, Madrid.

[18] MARHUENDA, P. G. (2006). «La evolución del endeudamiento de los hogares espanoles durante el decenio 1996-2005». RAE: Rev. Asturiana de Economía, (36), 141-170.

[19] MINISTERIO DE FOMENTO (2012). «Informe sobre el stock de vivienda nueva 2012 (Serie 2008-2011 revisada). Disponible en: http://www.fomento.es/NR/rdonlyres/ 88A7D54A-A73E-4C1C-9956-2A0DC1D0D399/122300/SVN_12.pdf.

[20] MULDER, C. H. y WAGNER, M. (2001). «The connections between family formation and first-time home ownership in the context of West Germany and the Netherlands». European Journal of Population, 17(2), 137-164.

[21] NAREDO, J. M (2004). «Perspectivas de la vivienda». Revista de Economía, 815, $143-$ 154.

[22] PAREJA-EASTAWAY, M. y SÁNCHEZ-MARTÍNEZ, M. T. (2014). «Private rented markets. Spain», en P. Kemp y A. Crook (eds.), Private rented markets in Europe. Londres, Edward Elgar Press, pp. 71-98.

[23] PAREJA-EASTAWAY, M. y SÁNCHEZ-MARTÍNEZ, M. T. (2012). «La política de vivienda en España: lecciones aprendidas y retos de futuro». Revista Galega de Economía, 21(2).

[24] PAREJA-EASTAWAY, M. y SÁNCHEZ-MARTÍNEZ, M. T (2011). «El alquiler: una asignatura pendiente de la política de vivienda en España». Ciudad y Territorio. Estudios Territoriales, XLIII(167), 53-70.

[25] PAREJA-EASTAWAY, M. y SÁNCHEZ-MARTÍNEZ, M. T. (2010). «European rental markets: regulation or liberalization? The Spanish case», en P. Arestis, P. Mooslechner y $\mathrm{K}$. Wagner, Housing Market Challenges in Europe and the United States-any solutions available. Hampshire: Palgrave Macmillan, 131-157.

[26] PAREJA-EASTAWAY, M. y SAN MARTÍN, I. (2002). «The tenure imbalance in Spain: the need for social housing policy». Urban Studies, 39(2), 283-295.

[27] PRIEMUS, H. (2011). «Renting in the United States: A Dutch perspective». Cityscape: A Journal of Policy Development and Research, 13(2), 159-?

[28] RODRÍGUEZ, J. (2015). «2015. Una recuperación gradual del mercado de vivienda en España». Ciudad y Territorio, Estudios Territoriales, XLVII(185), 575, cuarta época.

[29] SÁNCHEZ-MARTÍNEZ, T. (2002). La política de vivienda en España. Análisis de sus efectos redistributivos. Granada, Universidad de Granada.

[30] SCANLON, K. y WHITEHEAD, C. y FERNÁNDEZ ARRIGOITIA, M. (eds.) (2014). Social Housing in Europe. Londres, Wiley-Blackwell.

[31] TENLAW (2013). «Tenancy law and housing policy in multi-level Europe, national report for Spain», project reference: 290694, Funded under: FP7-SSH. European Commission. CORDIS: Disponible en http://www.tenlaw.uni-bremen.de/.

[32] TRABADA CRENDE, E. (2012). «El problema de la vivienda en una sociedad que se dualiza». Documentación Social. Revista de Estudios Sociales y Sociología, 165, 165188. 
[33] TRILLA, C. (2010). «Una reflexión sobre el modelo español de política de vivienda», en J. Leal, La política de vivienda en España. Madrid, Editorial Pablo Iglesias.

[34] VALVERDE, S. C. y FERNÁNDEZ, F. R. (2013). «El debate sobre la deuda hipotecaria en España». Cuadernos de Información Económica, 233, pp 13-22.

[35] WASSENBERG, F. (2004). «Large social housing estates: From stigma to demolition?». Journal of Housing and the Built Environment, 19(3), 223-232.

[36] WHITEHEAD, C. y SCANLON, K. (2007). Social Housing in Europe. London School of Economics and Political Science, Londres. 